\title{
ACTION STATIONS: \\ BIOLOGICAL COSMOPOLITANISM AT PLAY ON ONLINE SUPPORT GROUPS FOR GENETIC DISORDERS
}

Pauline Herbst ${ }^{1}$

\begin{abstract}
This paper examines how nineteen parents of children diagnosed with the inherited metabolic disorder, medium-chain acyl-coA dehydrogenase deficiency (MCADD), express their lived experience of the disorder on a closed New Zealand/Australia Facebook group. It shows how the diagnosis creates new geneticised subjects of both the child, and the parents who care for her, and that this diagnosis ties these families to the nation-state via the public health services. Bounded by fear that the disorder may present, their online identity is tied to the care of their asymptomatically, 'dis'ordered child, and exists simultaneously with that of other identities linked to the 'well' child. As cosmopolitan subjects they choose to move in and out of the socio-cultural environment constructed by the place in which they live and the health system linked to it, to engage with and in doing so, create an entirely new group based around a shared condition. I argue that these parents of children caught in limbo between pathology and health, engage in a voluntary and mutually hospitable set of relationships within this online support group, enabling them freedom from their biosocial identity in other aspects of their lives.
\end{abstract}

Keywords: Genetic disorder, medical anthropology, online community, biological cosmopolitanism, newborn screening

\section{INTRODUCTION}

In this paper I argue that biological cosmopolitanism can be used to describe the online expression of the lived experience of the parents of asymptomatic 'patients-in-waiting' (Timmermans et al., 2010). I build on Rapport's notion that, 'The cosmopolitan project entails the recognition that individuals are not beholden to any particular communitarian belonging or cultural rootedness 
for their sense of self and its fulfillment' (2010:184). Rapport borrows Riceour's rendering of a mobile 'narrative identity' (1996:8 quoted in Rapport, 2012:116) and 'narrative hospitality' to call for a space where an individual is free to be or become anything at any time with this mobile, free anyone seeking a lifeproject as opposed to an identity, an ideal echoed by Whyte (2009:13). I define the cosmopolitan individual and space as that incorporating the principles of choice, generosity, hospitality, and openness that enable an individual to be anyone (Skrbiš et al., 2013; Rapport, 2010), transcending genetic diagnosis. The cosmopolitan online space allows narrative hospitality to occur around this diagnosis on a temporal basis, thus paradoxically fixing and freeing the parents from an MCADD biosociality as they move within these permeable borders.

To do this, I analyse the evolving narratives of nineteen parents on an online Facebook support group, set up for the families of New Zealand resident children diagnosed with a rare metabolic disorder. Using data from participant observation and the afore-mentioned narratives, I show how and why their parents reach beyond the nation-state to a virtual and cosmopolitan Facebook group, perceived by them to be an open and tolerant space. I then examine how these parents engage with their identity as fixed, genetic subjects within this space, allowing them to become fluid, new cosmopolitan individuals outside of the Facebook group. Finally I suggest biological cosmopolitanism is a particular form of biosociality - it has been created by the need for parents to be able to disassociate from the underlying pervasiveness of the disorder, while still being able to discuss it with others sharing that biological experience when required.

\section{MCADD IN NEW ZEALAND}

The Expanded Newborn Screening Programme in New Zealand screens for 28 rare genetic conditions (Ministry of Health, 2015) that could result in severe, life threatening complications in the first few weeks of life. Medium-chain acyl-CoA dehydrogenase deficiency (MCADD) was included in an expanded newborn screening programme in 2006 and, to date, there are 46 children and young adults countrywide who have been diagnosed with the condition (Starship, 2015). The aim of screening is to detect affected newborns and treat them before symptoms develop. This creates patients who may remain asymptomatic but are always at risk if they have an infection or fast for any reason. When unwell they can become hypoglycaemic, suffer from brain disease and will often die if left untreated for a few hours in this state (Wilson et al. 2012:45). Once diagnosed, this is less likely to happen as parents are educated 
to feed the child a high calorie diet when unwell and if unsure, to go to hospital. Timmermans et al. use the term 'patients-in-waiting' to describe patients who 'hover for extended periods of time under medical attention between sickness and health... between pathology and an undistinguished state of "normalcy" (2010:409). The social impact of newborn screening includes the identification of the child according to its genetic result; and shock in the parents who are confronted with the 'Other' in the place of their 'perfect' child (Buchbinder et al., 2011; Fitzgerald, 2008; Grob, 2006; Rapp, 1988). As these authors observe, such a diagnosis leaves parents unmoored from the habitual rules governing a new infant.

The diagnosis of MCADD thus medicalises food and creates new molecularly defined subjects (Lock et al. 2007; Rose, 2001:12), biosocial geneticised subjects with enhanced responsibility to ensure the disorder remains asymptomatic (Rabinow, 1996, 1998). The diagnosis also extends to create citizens of the parents in three ways. Firstly, they are biological citizens who are both carriers of the disorder and thus responsible for their child's condition, as well as responsible for ensuring that symptoms do not develop by feeding children regularly (Novas \& Rose, 2000; Rose \& Novas, 2005). Secondly, these parents are aligned with the state - residency status within New Zealand entitles them to medical care for their children and thus leads to a reliance on the state as national citizens. Thirdly, they have an emotional and sensory attachment to one another based on their experiences and fears about the disorder (Trnka et al. 2013:3), creating a biosocial community of care. Food becomes treatment; meals an exercise in risk reduction. The infant or child cannot go for extended periods of time without food. For example, an infant under five months old should not go for longer than four hours without being fed, with this increasing by one hour as the child aged per month. At the age of one, most specialists advised it was safe to leave children without food for twelve hours overnight so long as they were well, had eaten normally throughout the day and went to bed on a full stomach ${ }^{2}$. If children are unwell, do not eat for any reason, or have diarrhoea or vomiting, they need to start an emergency regime of carbohydrates. If the children fail to keep this down or will not drink it they will be hospitalised and put on an IV of dextrose $\mathrm{e}^{3}$ until they are well and eating again. The strict feeding regime in the first year is both necessary and precautionary which I argue is driven by emotion, particularly fear that if for some reason the parent does not reach their self-defined feeding target, this could result in the death of their child.

As the parents try to incorporate precautionary measures into daily family routine, the relationship between the growing child's sense of agency, food 
and identity is linked to the disorder. The body of the child and related food practices become a contested space. Breastfeeding is the first point of contestation (Keenan et al., 2009) where the parent, particularly the mother, feels under pressure to feed the infant every few hours, which the baby may resist or physical constraints may restrict. Similarly family mealtimes and food practices become fraught with tension as toddlers and young children engage in 'normal' independent behaviour and choose not to eat (Cook, 2009; James et al., 2009). I observed that every experience, from whether to breastfeed, attend playgroup, or be around other babies with colds, is mediated through the lens of MCADD, with mothers in particular feeling anxious and judged by their peers. The children's agency also plays a part when they do not want to drink milk or eat. Parents feel criticised by extended family and friends for being hypervigilant and resort to either defending or hiding their fear that they could lose their child to the condition. As in other studies (Raspberry et al., 2007; Timmermans et al., 2010), I found that additional stresses include firstly, the diagnostic uncertainty of the disorder as neither specialists nor parents know if the disorder will become symptomatic and secondly, the conflicting messages parents receive from their own online research and from medical teams as they try to relay the potential severity of the disorder. In some instances, parents feel the lack of an embedded, place-based means of support which they cannot find in familial kinship structures, nor in the medical system available to them.

To find some sort of diagnostic closure, parents join online support groups, transcending time and space but joined together by a toss of biological fate. This negotiated transcendence is one bounded by the episodic nature of the disorder and grounded by the members' existing socio-geographical networks. If, as Cimini argues, virtual deliberation can best be understood dialogically (2010:404) then the meaning of MCADD is constructed and reproduced both on and offline. Facebook becomes a way to aggregate these voices and give form and shape to a formless disease (ibid:401). This fellowship is fluid and cosmopolitan in nature, representing a kind of space for human expression and for individual emancipation' (Rapport, 2012:75), where these newly defined genetic subjects can explore how others marked by the same disorder frame MCADD and in the process, themselves (Ching \& Foley, 2012:6). However the very reason this space appears so cosmopolitan, is that it is a representation of one facet of an individual's life at a static point and time, usually at those times that the MCADD diagnosis is uppermost in their minds. While the Facebook group creates possibilities for members to legitimise their subjective experiences it also locks them into the identity of a 'parent with an MCADDer', a phrase oft seen on the group (ibid.:2), a technoscientific identity they are 
continually negotiating and reconstructing through narrative (Ching \& Foley, 2012; Sulik, 2009; Wehling, 2011).

The indeterminancy of MCADD results in individuals dipping in and out of the online community, a shared space only when required, rather than a sustained daily interaction. The concept of biological cosmopolitanism describes a space where narrative hospitality (Rapport, 2012:117) fleetingly plays host to these subjects before they leave to take up their daily lived lives elsewhere. MCADD is both an interruption to daily life as well as an all-pervasive component. Although these parents are connected through a twist of genetic fate, I will show their membership of this community to be fluid, driven by fear and episodic need as the ambivalence of the disorder dictates. I argue that these families are engaging in a type of biological citizenship, one that allows them to park their biosocial identity within the support group, leaving them to rework this identity in other aspects of their life. I suggest that the narrative hospitality (Rapport, 2012) shared by those affected by MCADD paradoxically indicate a biological cosmopolitanism at play, both within the individual and the space itself.

\section{METHODS}

This research is part of a larger ethnographic project that seeks to discover how children born with MCADD understand and manage their condition and considers how MCADD is framed in the home, at school and in hospital. Ethical approval was obtained from the Human Disability and Ethics Committees (HDEC), approval number 14/NTB/47. A total of thirty-three children and young adults participated in the study, along with their immediate families, representing 72 percent of all children diagnosed with MCADD in New Zealand at the time of writing (Starship, 2013-2015). The findings in this paper are based on an examination of a closed, independent Facebook support group for New Zealand and Australian families with a child diagnosed with MCADD, as well as ongoing participant observation with selected families. The group was set up in May 2014 after I discovered two New Zealand participants on an international MCADD support group. The New Zealand support group is clearly identified as being part of the research project and as a result Facebook has become both a site of enquiry and a research method (Pink, 2011). While some members found out about the Facebook group from their participation in the larger project, others were directed to it by the Paediatric Metabolic Services team based at Starship Children's Hospital in Auckland, searches on Facebook and word of mouth. Support group members who were willing to take part in the research had to explicitly give permission, even if they were already par- 
ticipants in the overarching research project and equally, existing participants could choose not to take part in the Facebook component. This paper includes findings from seventeen New Zealand families who are both participants in the study as well as members of the group, and totals seventeen mothers and two fathers. I mostly use the terms mothers and parents interchangeably in my discussions in order to conserve the anonymity of the fathers on the group.

Each family contains at least one child with MCADD currently resident in New Zealand and under the care of the Starship Metabolic Services team. With the exception of one young person, all were diagnosed through a Newborn Screening Programme ${ }^{4}$ and were under 10 years old at the time of writing. In addition to the Facebook group analysis, I engaged in participant observation in participants' homes, during regular clinics held at regional hospitals, and during hospital admissions when a child was unwell. I also conducted multiple open-ended interviews with parents, jointly and separately, with topics covering: personal reflections on diagnosis; decisions around infant feeding and health; reactions from social networks; choices in relation to childcare and schooling; personal reproductive choices after the discovery of being a carrier of MCADD; mealtimes and feeding; the management of the child's health when unwell and personal experiences during a hospital admission. These interviews were conducted in person during participant observation as well as via multiple telephone and Skype conversations, and varied in length from fortyfive minutes to three hours. I have also observed and been a part of families' communication networks when a child is unwell; texts, Facebook posts and telephone conversations when in hospital. Many of the aforementioned topics were spontaneously referred to on the Facebook group.

Analysis of the Facebook group is ongoing, with members contributing to a vibrant, dynamic community that waxes and wanes as MCADD features more or less prominently in their lives. Whilst the bulk of this paper is based on the activity of the participants on the Facebook group, it does not privilege the online locale (Boellstorff, 2012), as I conducted participant observation both online and offline. Both have been analysed for common themes using an open coding approach (Emerson at al., 1995:143) with the Facebook activity interpreted as one representation of this experience. Anonymity on Facebook is hard to achieve, however by making the group private, non-members of the group are unable to browse through the comments, and these conversations do not appear on the participants' personal feeds. I have also refrained from copying statements verbatim to prevent search engines from finding them and have used pseudonyms. Finally, I was an active member of these groups, although I tended to post my observations after the rest of the research community. 
This Facebook page resonates with Rapport's 'imagin[ing of] a liberal-cosmopolitan social space... guaranteeing the telling of a diversity of stories as well as inculcating a generosity, hospitality and mutuality in their being heard' (2012:119). The capacity for members to freely express their concerns about the effect of the disorder on their child's lives particularly around feeding was telling, this was something that was reportedly trivialised by some extended family members as 'it's no big deal, you just have to eat' and 'just get on with it'. Parents expressed a self-consciousness and defensiveness about feeding their children, an act that is so commonplace and routine to be deemed of no special consequence. As Michelle, the mother of a four-month-old with MCADD posted: 'Family, and friends try to be supportive and all that but I feel they just don't quite understand how serious it could be if he is not fed!!.

Skrbiš et al's (2013) expression of the optimistic face of cosmopolitanism can be usefully applied to this Facebook community, by arguing that the aggregate of their online interactions (Cimini, 2010) creates a cosmopolitan space, within which participants could overcome their shock of diagnosis by joining a safe online community that supports this difference. While parents wished their child did not have the condition, they chose to frame this in positive terms; the majority expressing a sense of relief or 'luck' that their children have MCADD as opposed to any of the other disorders in the expanded Newborn Screening Programme. However due to the ambiguous, asymptomatic nature of the disorder they also expressed a sense of guilt and anxiety in using public health resources when there are 'others out there who are far worse off' (Faith, mother of a five-year-old with MCADD). To overcome this, they used their online community to welcome others who shared the condition; offering tips and ideas from daily lived experience and seeking clarification and reassurance about medical advice received.

\section{Place for place: the New Zealand health system}

Skrbiš et al. note that 'There is place for place in cosmopolitanism' (2013:29), and this was also relevant for participants who were bound to the nation-state of New Zealand, as citizens, or as residents with children under the care of the national Paediatric Metabolic Team based in Starship Hospital, Auckland. Their sense of belonging to the Facebook group does indeed 'transcend the immediate and local' (Skrbiš et. al., 2013:29) but this social group exists in tension with the New Zealand state and in fact, it could be said, would not exist without that tension. This is evident from Maya's post: 
So glad to find this group. Everything on the net seems to be US and doom and gloom and treatment and advice is so different from what we were told. It's great to have other NZ parents to talk to. We're told so many different things, even from people at the same hospital clinic that I feel I have to double check everything.

Part of this affiliation to New Zealand was access to free medical care for children. All parents expressed gratitude for this care, however the neoliberal New Zealand health care system, as with others in the world, does encourage patients (and their parents) to take responsibility for their own healthcare (Fitzgerald, 2004; Park, 2009). As Trnka et al. suggest, 'New Zealand parents are structurally encouraged - and one might even argue required-to take up more active roles in determining their child's health needs' (2012:4). In Herbst (2014) I examine the responsibilisation of these parents, and how they chart a fraught course between the poles of well and unwell. They do this by shedding some responsibilities and prioritising others towards the goal of preventing symptoms from presenting until the child is admitted to hospital and becomes the responsibility of the healthcare system. While some parents are frustrated that they need to make the decision to bring their child in to hospital, others find the New Zealand system accessible and reassuring as compared to their paternalistic experiences in the UK. Unlike many biosocial communities, parents did not join the Facebook group in order to mobilise for better health services within New Zealand, rather they were seeking Rapport's aptly labelled narrative hospitality.

\section{Narrative hospitality in action}

From my initial observations, Facebook posts fell into ten main themes, which I have categorised into three groups: i) maintenance, ii) active management and iii) social interaction. Maintenance concerned the daily precautionary measures mothers took to keep the disorder asymptomatic and included posts about food such as dietary queries, tips on fussy eating, mealtime complaints, breastfeeding, and bottle feeding. Extracts from one conversation read as follows:

Marie: ...our soon to be 4 is a fussy little boy, brekkie is hard and tea is a long ordeal. pasta, pasta, pasta he loves pasta, just gotta hide the veges in it.

Christina: Michael is a terrible eater so mealtimes are a struggle and refuses to eat when tired. 
Fiona: I know how much of a struggle meal times can be... John has recently got a lot better but at stages he was nearly just surviving on sugary drinks.

Christina: It's really difficult when they refuse so much. I would always start the meal with whatever I wanted him to try, but always back it up with the fall-back of enough bits of penne pasta.

A sub-theme under maintenance included discussions about daily parenting, vaccinations, dental visits, and Plunket child health services; decisions that every parent has to make but that these parents look at through the lens of MCADD. These themes also shift from maintenance to active management and back depending on the child's health. On one occasion, reported chickenpox at a birthday party led to Michael, a three-year-old with MCADD, quickly getting his chickenpox vaccination, something his mother Christina had planned to do as per the advice to routinely obtain all vaccinations possible to prevent ill health that might then lead to a hospitalisation. This then prompted a sharing of narratives and queries from mothers with younger children, culminating with the following observations about health:

Fiona: We weren't offered chickenpox vaccination and spent 6 days in hospital when our MCADDer caught it from his big brother.

Christina: When they are small and don't have much of an immune system I just think it's easier to keep them out of the way of others that have colds and bugs, just so you can avoid the stress of having to go in - many would say 'oh it's good for them to be exposed, you don't want to wrap them in cotton wool blah blah blah.... but for those who pay a bigger price if they get poorly its different, so ignore all that! Most are ignorant of the facts so we have to forgive that. There no way around it, it is a hard time learning and dealing with it, but you will and you'll be an expert on the subject!

The majority of the posts concerned the second category, active management of the disorder, when the child was unwell or admitted to hospital. These would follow an illness trajectory, starting with 'action stations', where the mother would alert other members that their child was sick and on two-hourly Polycal 'feeds', usually in liquid form as this is easier for a sick child to digest. The parents would post regularly to support the mother (and occasionally father) who were strictly monitoring the volume of Polycal or snacks the child was having, waking them up every few hours to do so; a traumatic experience for 
child and parent. This particular facet of Facebook was embedded in actively managing the body of the child with MCADD, with not much reference to parents' needs, except on how their own stress or 'bad' practice might impact on the child's feeding. Frequent issues aired during an illness episode were the volume the child needed to consume and the difficulty in waking them and tempting them to drink or eat at all. Implicit but not stated was the exhaustion of the mother, the underlying concern they had about what would happen if they could not wake the child and the tension they felt between not wanting to go to hospital but knowing that if it came to that, it was the best option for the child. The following post by Maggie at around four in the morning highlights some of this pressure:

Hey I'm up with my 4.5 month old with MCADD he had a snotty nose yesterday and last night put him to bed at 1opm after a feed, woke him at ram and he's got slight cough as well as his snotty and runny nose. He is running a temp of 38.28 by my thermometer, gave pamol at 2:20 which he coughed and lost 10 mins later mixed with saliva but no milk with it (not vomiting) had done poo seems to be pooing a lot more in past 12 hours but looks normal and no smell just going more frequent! Don't think he has diahorrea. He is exclusively breastfed and still feeding well

Had hospital admission last month due to a cold and not feeding at all

Any advice if anyone is up ... May call on consultant yet ... will if temp stays up

Excretions by children were a concern for all parents but what seemed to be more worrying was the unknown, the liminality, the message that 'the child may be ok, the child may not, to be safe, bring them in' (Mark, father of a seven-year-old with MCADD). In interviews parents reported it was almost easier when the child was vomiting as then it was very clear that they had to take them to hospital. Here Maggie was reaching out to Facebook as a 'metaperson', using the group as a 'witness to suffering that [seemed to] be cathartic in its own right' (Miller, 2011:172). She exemplifies a hesitance on the part of parents to phone specialists outside of office hours to get advice despite New Zealand being one of the few places in the world where parents are enabled to ring the metabolic specialist on call directly. Parents considered themselves lucky to have this support and reported a reluctance to abuse this, preferring to take responsibility themselves for as long as possible. This was especially 
true of families outside of Auckland, where the Paediatric Metabolic Service is based. Parents turned to the Facebook site instead, inquiring about percentages of polycal to use, or alerting 'action stations' to generate a flurry of responses in turn until the child was either well again, or despite all efforts, hospitalised such as in the case of Maggie, who later reported:

Haha all turned to custard guys we are now in hospital! He was only taking small feeds this morning then refused breast altogether and now we're in hospital with the stubborn little toad! He is on a drip got him to feed a little amount about half hour ago now he's sound asleep.

Activity on the group would escalate in response to the member in need, then cease entirely until the next crisis or query as in the case of Ngaire: 'Cue 4:ooam raging fever 38.8 , small vomit. We still don't have a line... Should I be pushing for one?? More is staying in than coming out but he has got a fever.... Unsure, followed a few hours later after reassurance and advice from 14 people by: 'After crying for $55 \mathrm{mins}$ after the $\mathrm{Ng}$ tube was put in he is finally sleeping. Sensitive wee boy'. MCADD is episodic in time and space and after time, parents reflect on it 'getting easier'. Although they remain ever vigilant, they do not have to raise responsibility until the condition presents. Timmermans et al. report that 'the prolonged use of ambivalent messages make it difficult for parents to relax' (2001:409) even when the child is older and specialists recommend it. This was apparent with these parents.

The final category, social interaction, includes introductions where new members were welcomed and shared their personal stories (and through doing so validated their membership of the group). It also extends to sharing diagnoses of new additions to the family, news of birthdays (spent both in and out of hospital,) sporting achievements; and querying information, prescriptions and medical advice given by specialists. Despite the title of the category there was no evidence of daily conversation, or interactions outside of the unspoken mandate to focus on MCADD. This was a space for testimony, for shared experience, for the recognition of the other within oneself (Rapport, 2012). These individuals shed the skin of their geneticised identity, leaving it in the hands of the Facebook group. They then returned to their daily lives with MCADD again reduced to a shadow with no social pressure or commitment to binding reciprocal relations. This does not mean that no reciprocity existed, to the contrary, mothers often commented what it was like to feel bewildered and alone with no one to turn to and wished the group had existed when they first found out the diagnosis. They then would share their memories of past 
and current experiences to guide others on the start of their journeys. This was however, entirely voluntary and bounded by the condition. I discuss the experiences in this social category further in the next section to show how the nature of this space enables these parents to recreate themselves as cosmopolitan individuals.

\section{LOCATING ONESELF: THE NARRATIVE IDENTITY}

To address this I turn to the individual, using Miller (2011) and Rapport's (2012) readings of Ricoeur's narrative identity $(1984 ; 1996)$. These scholars' interpretations speak directly to these apparent contradictions. Miller explores Facebook time as narrative time (2011:192), highlighting Facebook's reality show-like quality, which for him 'confirms Ricoeur's argument that we relate best to people when we encounter them within established genres of narrative' (ibid.: 193). These people turn to the site when actively managing the disorder, using narrative to share their experiences and in doing so, constitute their own humanity (ibid.:192).

The previous section has documented how members of the Facebook group created the narrative webs of suffering and experience that created the community. I found that members of the group posted as parents responsibilised to manage MCADD. They introduced themselves through their children's condition, marking their difference and by extension, their cosmopolitan identity (Sypnowich, 2005). This pattern was unprompted and included information about their children, which one had MCADD, their age, an emotive response to the diagnosis, and what they felt about the local group:

Rachel: Hi everyone. Seeing as I'm new to the group, I wanted to share a bit more about our experience with MCADD. I'm blessed to have two mcadd kiddies, both girls 1 and 2 [years old]. It's nice to have a close to home fb group for mcadd.

Lily: welcome to the group, it's great to talk to other parents who understand

Each post would result in a minimum of ten responses. They would vary in length and detail from an initial few lines to an extensive personal narrative and often, this depended on the age of the child, with those with infants expressing a great deal of concern when compared to the parents with older children. 
Rose: I live in Northland and have a 2 week old baby. I was on such a high then bam... I crashed when I was told she has MCADD. I spent almost a week in shock. I couldn't believe this was happening. I now realise I need to be strong. The strict feeding schedule scares me as I have only myself to rely on. Her dad and I aren't together any more. I hope I may share my journey with you and look forward to any support and advice you can offer during my hardest times $\mathrm{x}$

This posting was followed by several welcoming, supportive responses. Often the mother would post a picture of their child, confirming the sense that this was a safe environment with other parents united in the cause of caring for these 'unique' children and highlighting the local nature of the group. Some framed the disorder in a positive light, displaying 'I have a child who's rare' banner on their profile or expressing the uniqueness of their children. If one was to consider Wardle's (2010) concept of cosmopolitanism as representing the transformation of both oneself and one's world, these parents are simultaneously the parents of a 'normal' child that has nothing overtly wrong with her and the worried parents of a child with a rare disorder, feeling isolated and misunderstood by the society within which they live. Thus they tap in and out of these global support groups when they need to, a need that is particularly great during infancy and periods of illness.

\section{Within biosociality and biological citizenship}

Activism and responsibilisation are both key aspects of discussions of biological citizenship (Fitzgerald, 2008; Heath et al., 2007; Rose et al., 2005; Rose, 2009); summed up by Whyte as 'combin[ing] identity politics with biopower. The Foucauldian interest in the state and the self, the two poles of biopower, is enlarged with a focus on biosocial groups that make claims for inclusion and justice' (2009:12). While parents do feel an increased responsibilisation, this too slides along a continuum and with treatment relatively simple medically (the child eats or goes on an IV), parents do not report a sense of injustice. Thus while biological citizenship does the work of describing and deconstructing an initial molecularised identity, the concept of biological cosmopolitanism works with it hand-in-hand to highlight the limits of this citizenship, informed by the shifting, liminal facets of the disorder and made visible through the mirroring activity of the individuals on the Facebook group.

As Whyte argues: 'Between the two poles of identity politics, the collective and the personal, different balances are made between common political efforts and individual efforts to rework a devalued identity' (2009:8). I suggest that 
the ambiguity of the disorder, coupled with the fluid nature of Facebook as a site of community, lends itself to a discussion of biosociality beyond that of health identities and subjectivities created through medical technology (in the form of newborn screening) (Rabinow, 1996). I argue that these individuals do not seek to forge a collective identity based on this diagnosis (Rapp, 1999:302). They never meet in person and seem happy to move in and out of the space as they wish. Or as Rapport expresses 'one accommodates the other without presuming to know the other' (2012:87). Neither do they lobby for their disease, more resources, research or reform. Their needs are emotional, underscored by an often unconscious fear that their child will die if they do not eat, a fear driven by the non-quantifiable nature of how much energy a child has used up. This fear builds affect in the community.

\title{
Narrative affect and individual emotion
}

\begin{abstract}
April: Anyway now Heath is 5 months old and so far he hasn't been sick at all, just happy and healthy. As my partner works long hours, it has been tiring for me making sure Heath sleeps no longer than six hours. He will usually go down at about 12:30am and then I will wake him at 6am-which he is not happy about. We live an hour away from the hospital and I am feeling anxious about the first time we will need to make that trip, mainly because I may be on my own. I have a lot of 'what ifs' that go through my head but just try to remind myself I know what to do and that things will be ok.
\end{abstract}

Sarah Ahmed explores 'emotions on the "surface" of individual and collective bodies,' (2014:1), arguing that emotions have mobility, with this movement not necessarily cutting the body off from its place but also 'connecting bodies to other bodies' (ibid:11). Particularly pertinent is her discussion of the affective politics of fear and how this too contains temporal dimensions, that fear is tied to an anticipation of being hurt or injured, it 'impresses upon us in the present, as an anticipated pain in the future' (ibid: 65). She argues that even if this anticipated hurt does not occur, which in the case of these parents is hospitalisation, brain damage or the loss of their child, the anxiety caused by the fear sticks to the diagnosis. This is exemplified by Susan:

Susan: when I found out I was very upset not knowing about her condition everything was going through my mind when before that she was sleeping through the night. since then she has been in hospital twice and I was very scared that she had to have tubes in through her nose to get to her tummy to feed and all I wanted was 
for her to get better and was hard to see as there was nothing I could do but be there for her.

Susan and April had different experiences of the disorder's effect on their lives but were united by the emotion of fear, fear of the unknown and what might happen, a constant state with this disorder. Their and other mother's experiences of managing the disorder within their existing social networks opened them to criticism and scrutiny, even if this was sometimes a defensive and reflective observation on their part. As Ahmed explains: 'emotions may involve readings of such openness as spaces where bodies and worlds meet and leak into each other,' (2014:69); in the familial lived experience of MCADD, the body shrinks from fear. If the meaning of MCADD is constructed and reproduced through dialogue and social interaction (Ching and Foley, 2012; Cimini, 2010) then the negation of it during interactions with family and community in daily life should reduce MCADD to a negligible footnote in one's life. But it does not, MCADD is a shadow that is always there, its visibility just changes based on temporal and environmental factors. I argue that by creating and sharing their own narratives of this fear, they confine its 'stickiness' to the site, thus managing their unwanted biological citizenship and maintaining the potential to be Rapport's anyone outside of this space.

\section{CONCLUSION}

As Miller says: 'Facebook does not exist in isolation. No one lives just on Facebook... It is one of the structures of social networking... There is no such thing as Facebook from the perspective of cultural relativity. Facebook is only the aggregate of its regional and particular usage (2011:163). If cosmopolitanism does incorporate 'individuals marked by difference', and free to choose the projects pertinent to their own life-projects/ stories, then these parents, biological citizens marked by genetic difference, are choosing to incorporate and shed this identity. Not at will, but when required. The space they have created, a community formed by an online web of interweaving narratives and supportive comments, is thus cosmopolitan in nature, being voluntary, transient, open and accepting.

These individuals are citizens of this space, framed by the disorder and the New Zealand health system they rely on for the ongoing medical care of their children. Although a genetic disorder is intrinsic to membership of this group, it is not an acknowledged sustained constant in these individuals' lives, and indeed, contact between others in New Zealand dealing with the disorder is limited only to this online space. These individuals' identification with the 
disorder and their interaction in this space is fluid and rather episodic - used as a means of maintaining control against an unknown. This creates a bond of emotion, binding them temporarily together when the community at large requires. Based on the ethnographic analysis of the activity on this Facebook support group, I suggest biological cosmopolitanism as a means to envisioning communities and individuals affected by chronic, presymptomatic, genetic disorders. Rather than permanently taking on the ill-fitting biosocial mantle of an identity defined by illness, an individual can choose to become a cosmopolitan anyone, temporarily inhabiting what is perceived to be a safe space defined by MCADD, parking that aspect of identity in order to ignore it in the other spheres of his or her life. This activity and space is co-negotiated and ratified over time and multiple interactions; to paraphrase Skrbiš et. al., (2013) on cosmopolitanism, a life line to use when this difference punches holes in ordinary life, a means of choosing how to deal with this prediagnosed fate, and a hospitable space where futures can be celebrated and bold ideas shared.

\section{ACKNOWLEDGEMENTS}

I would like to thank the families that participated in this project. My doctoral studies have been financially supported by the University of Auckland, AMP, and the Auckland Medical Aid Trust (Амат).

An earlier version of this paper, entitled Thanks for the add: The construction of identity through illness narratives was presented at the joint conference of the Association of Social Anthropologists of Aotearoa/New Zealand and the Australian Anthropology Society, in Queenstown in November 2014.

I would like to thank Prof. Julie Park, Assoc. Prof Judith Littleton, Assoc. Prof. Ruth Fitzgerald, Dr. Anne Pelzel and Dr. Steve Matthewman for their insightful comments.

NOTES

1 Pauline Herbst is a PhD candidate in the Department of Anthropology at the University of Auckland. Her research interests include medical anthropology, the anthropology of childhood, identity, visual anthropology and media anthropology.

Email: p.herbst@auckland.ac.nz

2 The frequency of this varies according to the age of the child and from specialist to specialist. For example, the parents in this study were advised to feed their 
infants according to a rough estimate of their age. Some specialists advise less or more time depending on their training and country of origin/ practice. In each case the general health of the individual is taken into account.

3 A simple sugar chemically identical to glucose (blood sugar) that is made from corn. This is dissolved in solutions for intravenous use.

4 The majority of the children were born in New Zealand. One of the children was diagnosed after his younger sibling was picked up in Newborn Screening. A further two were diagnosed in Australia and the United Kingdom respectively, under those countries' newborn screening programmes.

\section{REFERENCES}

Ahmed, Sara. 2014. The Cultural Politics of Emotion. Edinburgh: Edinburgh University Press.

Boellstorff, Tom. 2012. Ethnography and Virtual Worlds: a Handbook of Method. Princeton: Princeton University Press.

Buchbinder, Mara and Stefan Timmermans. 2011. 'Medical Technologies and the Dream of the Perfect Newborn.' Medical Anthropology 30 (1):56-80. doi:10. 1080.01459740 .2010 .531065 .

Ching, Cynthia Carter and Brian Foley. 2012. Constructing the Self in a Digital World. Cambridge: Cambridge University Press.

Cimini, Nicholas. 2010. 'Struggles online over the meaning of "Down"s syndrome': A “dialogic" interpretation.' Health. 14(4):398-414.

Cook, Daniel. 2009. 'Children's Subjectivities and Commercial Meaning: The Delicate Battles Mothers Wage when Feeding their Children.' In Children, Food and Identity in Everyday Life, edited by Allison James, Anne Trine Kjorholt and Vebjørg Tingstad. Basingstoke: Palgrave.

Emerson, Robert, Rachel Fretz, and Linda Shaw. 1995. Writing Ethnographic Fieldnotes. Chicago: University of Chicago Press.

Fitzgerald, Ruth. 2004. 'The New Zealand Health Reforms: Dividing the Labour of Care.' Social Science \& Medicine 58 (2):331-341. doi:10.1016/So2779536(03)oo201-6. 
Fitzgerald, Ruth. 2008. 'Biological Citizenship at the Periphery: Parenting Children with Genetic Disorders.' New Genetics and Society 27 (3):251-266. doi:10.1080/14636770802326927.

Grob, Rachel. 2006. 'Parenting in the Genomic Age: The "Cursed Blessing" of Newborn Screening.' New Genetics and Society 25(2):159-170. doi:10.1080/14636770600855218.

Heath, Deborah, Rayna Rapp and Karen-Sue Taussig. 2007. 'Genetic Citizenship.' In A Companion to the Anthropology of Politics, edited by David Nugent and Joan Vincent. Blackwell Publishing. Blackwell Reference Online. doi:10.1111/ b.9781405161909.2007.00011.x.

Herbst, Pauline. 2014. 'Easily Managed. Competing Responsibilities and Healthcare in Families Living with MCADD'. Competing Responsibilities. The Politics and Ethics of Responsibility in Contemporary Life. Victoria University of Wellington International Conference: Wellington, New Zealand.

James, Allison, Penny Curtis, and Katie Ellis. 2009. 'Negotiating Family, Negotiating Food: Children as Family Participants.' In Children, Food and Identity in Everyday Life, edited by Allison James, Anne Trine Kjorholt and Vebjørg Tingstad. Basingstoke: Palgrave.

Keenan, Julia and Helen Stapleton. 2009. 'It Depends what You Mean by Feeding on Demand: Mothers Accounts of Babies Agency in Infant Feeding Relationships.' In Children, Food and Identity in Everyday Life, edited by Allison James, Anne Trine Kjorholt and Vebjørg Tingstad. Basingstoke: Palgrave.

Lock, Margaret, Julia Freeman, Gillian Chilibeck, Briony Beveridge, and Miriam Padolsky. 2007. 'Susceptibility Genes and the Question of Embodied Identity'. Medical Anthropology Quarterly 21 (3):256-276. doi:10.1525/ maq.2007.21.3.256.

Miller, Daniel. 2011. Tales from Facebook. Cambridge, UK; Malden, MA: Polity Press.

Ministry of Health. National Screening Unit. 2015. Newborn Metabolic Screening Programme. New Zealand. http://www.nsu.govt.nz/health-professionals/1012.aspx.

Novas, Carlos and Nikolas Rose. 20oo. 'Genetic Risk and the Birth of the So- 
matic Individual.' Economy and Society 29(4):485-513. doi:10.1080/ 03085140050174750.

Park, Julie. 2009. 'Concepts of Human Nature, Personhood and Natural-Normal in New Reproductive Technology Discourses in New Zealand'. Anthropologica 51:173-186. http://www.jstor.org.ezproxy.auckland.ac.nz/stable/25605465.

Pink, Sarah. 2011, 'Images, Senses and Applications: Engaging Visual Anthropology', Visual Anthropology 24 (5): 437-454. doi:10.1080/08949468.2011.604611.

Rabinow, Paul. 1996. 'Artificiality and Enlightenment: From Sociobiology to Biosociality'. Essays on the Anthropology of Reason, Princeton NJ: Princeton University Press.

Rabinow, Paul. 1998. 'Genetic and Molecular Bodies.' In Philosophical Designs for a Socio-Cultural Transformation: Beyond Violence and the Modern Era. Edited by Tetsuji Yamamoto, edited by Ecole des hautes études en sciences culturelles, 135-150. Tokyo, Japan: École des hautes études en sciences culturelles (with Rowman \& Littlefield).

Rapp, Rayna. 1988. 'Chromosomes and Communication: The Discourse of Genetic Counselling'. Medical Anthropology Quarterly 2 (2):143-157. doi:10.1525/ maq.1988.2.2.02aooo40.

Rapp, Rayna. 1999. Testing Women, Testing the Fetus [Electronic Resource]: The Social Impact of Amniocentesis in America, edited by Inc ebrary. New York: Routledge, 1999.

Rapport, Nigel. 2010. 'Cosmopolitanism and Liberty'. Social Anthropology. 18 (4): 464-470. doi:10.1111/j.1469-8676.2010.00131.x.

Rapport, Nigel. 2012. 'Cosmopolitanism: Actors, Relations and Institutions Beyond the Communitarian.' In Community. Cosmopolitanism and the Problem of Human Commonality, edited by Vered Amit and Nigel Rapport, 75-199. London: Pluto Press.

Raspberry, Kelly and Debra Skinner. 2007. 'Experiencing the Genetic Body: Parents' Encounters with Pediatric Clinical Genetics.' Medical Anthropology 26 (4):355-391. doi:10.1080/01459740701619848.

Ricoeur, Paul. 1996. 'Reflections on a New Ethos for Europe.' In Paul Ricoeur: The 
Hermeneutics of Action, ed. R. Kearney. London: Sage.

Ricoeur, Paul. 1990, c1984. Time and Narrative. Translated by Kathleen McLaughlin and David Pellauer. Chicago: University of Chicago Press. http://hdl. handle.net.ezproxy.auckland.ac.nz/2027/heb.04912.0001.001.

Rose, Nikolas. 2001. 'The Politics of Life Itself.' Theory, Culture \& Society 18 (6):1-30. doi:10.1177/02632760122052020.

Rose, Nikolas 2009. 'Normality and Pathology in a Biomedical Age.' The Sociological Review 57: 66-83. doi:10.1111/j.1467-954X.2010.01886.x.

Rose, Nikolas and Carlos Novas. 2005. 'Biological Citizenship'. In Global Assemblages: Technology, Politics and Ethics as Anthropological Problems, edited by Aihwa Ong and Stephen Collier. Malden, MA: Blackwell Publishing.

Skrbiš, Zlatko, Ian Woodward, Chris Rojek, Martine Jonsrud, Catja Pafort, Katherine Haw, and Wendy Scott. 2013. Cosmopolitanism: Uses of the Idea. London: Sage.

Starship Metabolic Services. 2012-2015. Personal Communication. Auckland, New Zealand.

Sulik, Gayle. 2009. 'Managing Biomedical Uncertainty: the Technoscientific Illness Identity'. Sociology of Health \& Illness 30 (7):1059-1076. doi:10.1111/j.14679566.2009.01183.x.s.

Sypnowich, Christine. 2005. 'Cosmopolitans, Cosmopolitanism, and Human Flourishing.' In Gillian Brock and Harry Brighouse (eds.). The Political Philosophy of Cosmopolitanism, Cambridge: Cambridge University Press. 55-74.

Timmermans, Stefan and Mara Buchbinder. 2010. 'Patients-in-Waiting: Living between Sickness and Health in the Genomics Era.' Journal of Health \& Social Behavior 51 (408): 408-423. doi:10.1177/0022146510386794.

Trnka, Susanna, Christine Dureau and Julie Park. 2013. Sense and Citizenships: Embodying Political Life. New York, London: Routledge.

Trnka, Susanna. and Laura McLauchlan. 2012. 'Becoming 'Half a Doctor': ParentExperts and the Normalisation of Childhood Asthma in Aotearoa New Zealand.' Sites 9 (2):3-22. 
Wardle, Huon. 2010. 'A Cosmopolitan Anthropology?'. Social Anthropology 18 (4):381-388. doi:10.1111/j.1469-8676.2010.00120.x.

Wehling, Peter 2011. 'The "Technoscientization" of Medicine and its Limits: Technoscientific Identities, Biosocialities, and Rare Disease Patient Organizations'. Poiesis Prax 8: 67-82. doi:10.1007/s10202-011-0100-3.

Whyte, Susan Reynolds. 2009. 'Health Identities and Subjectivities: The Ethnographic Challenge'. Medical Anthropology Quarterly 23(1):6-15. doi:10.1111/j.1548-1387.2009.01034.x.

Wilson, Callum, Nicola J. Kerruish, Bridget Wilcken, Esko Wiltshire, Kathy Bendikson, Dianne Webster. 2012. 'Diagnosis of Disorders of Intermediary Metabolism in New Zealand before and after Expanded Newborn Screening:2004-2009'. The New Zealand Medical Journal. 125 (1348): 42-49. 